\title{
COMPARACIÓN DE MÉTODOS DE INOCULACIÓN DE Fusarium solani f. sp. passiflorae EN PLANTULAS DE MARACUYÁ (Passiflora edulis f. flavicarpa)
}

\section{COMPARISON OF METHODS OF INOCULATION OF Fusarium solani f. sp. passiflorae IN SEEDLINGS OF PASSION FRUIT (Passiflora edulis f. flavicarpa)}

\author{
Carolina Ángel-García ${ }^{1}$, Jacobo Robledo-Buriticá ${ }^{2}$, Jairo Castaño-Zapata ${ }^{3}$
}

\begin{abstract}
${ }^{1}$ Ingeniera Agrónoma, Grupo de Investigación y Proyección Producción Agropecuaria (GIPPA). Universidad de Caldas, Manizales, Colombia, e-mail: carolina.501315331@ucaldas.edu.co; ${ }^{2}$ Ingeniero Agrónomo, Grupo de Investigación y Producción Agropecuaria (GIPPA). Universidad de Caldas, Manizales, Colombia, e-mail: jacobo.501220070@ucaldas.edu.co; ${ }^{3} \mathrm{Ph} . \mathrm{D}$. . en Fitopatología, Profesor Titular, Facultad Ciencias Agropecuarias. Universidad de Caldas, Calle 65 No. 26-10, Manizales, Colombia, e-mail: jairo.castano_z@ucaldas.edu.co
\end{abstract}

\author{
Rev. U.D.C.A Act. \& Div. Cient. 21(1): 23-31, Enero-Junio, 2018 \\ https://doi.org/10.31910/rudca.v21.n1.2018.659
}

\section{RESUMEN}

El maracuyá es una especie susceptible a patógenos, como Fusarium solani f. sp. passiflorae, causante de la secadera, llegando a causar pérdidas entre 90 y $100 \%$, en cultivos comerciales en Colombia. Debido al desconocimiento de un método de inoculación eficiente para evaluar germoplasma de maracuyá contra este patógeno, se planteó este estudio, cuyo objetivo fue comparar cuatro métodos de inoculación de F. solani f. sp. passiflorae MViRi01 en plántulas de maracuyá (Passiflora edulis f. flavicarpa), cultivadas a $29^{\circ} \mathrm{C}$, con un fotoperiodo de 12h. Los tratamientos fueron: incisión en el tallo $\left(T_{1}\right)$, inmersión de raíces $\left(T_{2}\right)$, inyección en el tallo $\left(T_{3}\right)$ y cribado en tubos de ensayo modificado $\left(\mathrm{T}_{4}\right)$. Se estimó la incidencia de la enfermedad y el periodo de incubación del hongo. Los métodos evaluados mostraron diferencias altamente significativas $(\mathrm{P}<0,001)$. F. solani f. sp. passiflorae infectó raíces, tallo y hojas, causando estrangulamiento ascendente y descendente del tallo. Se obtuvo $100 \%$ de incidencia de la enfermedad con los tratamientos $T_{1}$ (incisión) y $\mathrm{T}_{4}$ (cribado). En $\mathrm{T}_{4}$, el periodo de incubación del hongo fue 2,4 días y en $\mathrm{T}_{2}$ (inmersión), de 19 días. La muerte de las plántulas ocurrió 12 días después de inocular los tratamientos $T_{1}$ y $T_{3}$ (inyección). La emisión de raíces adventicias en las plántulas se indujo inyectando el patógeno ( $\left.\mathrm{T}_{3}\right)$. Los métodos apropiados para inocular Fusarium sp. en plántulas de maracuyá fueron el cribado en tubos de ensayo modificado y la incisión en el tallo, debido a la homogeneidad en los resultados y la replicabilidad.
Palabras clave: Nectria haematococca, colonización, incubación de enfermedades, patogenicidad. Thesaurus: aims. fao.org/es/agrovoc.

\section{SUMMARY}

Passionfruit is a species susceptible pathogens such as Fusarium solani f. sp. passiflorae, causal agent of Passiflora collar rot, which can cause yield losses between 90 and 100\% in commercial crops in Colombia. Due to lack of knowledge of an efficient inoculation method to evaluate germplasm of passionfruit against this fungus, it was designed this study, whose objective was to compare four methods of inoculation of $F$. solani f. sp. passiflorae MViRi01 in passionfruit seedlings (Passiflora edulis f. flavicarpa) cultivated at $29^{\circ} \mathrm{C}$ and 12-hours of photoperiod. The treatments were: stem incision $\left(T_{1}\right)$, root immersion $\left(T_{2}\right)$, stem injection $\left(T_{3}\right)$, and a modified test-tube screening methodology $\left(\mathrm{T}_{4}\right)$. Disease incidence and incubation period of the fungus was evaluated. The assessed methods showed highly significant differences $(P<0.001)$. $F$. solani f. sp. passiflorae infected roots, stem, and leaves causing stem ascending and descending strangulation. Both $\mathrm{T}_{1}$ (incision) and $\mathrm{T}_{4}$ (screening) treatments showed $100 \%$ of disease incidence. The incubation period of the fungus in $T_{4}$ was 2.4 days and in $T_{2}$ (immersion) 19 days. The death of the seedlings occurred 12 days after inoculation in $T_{1}$ and $\mathrm{T}_{3}$ (injection) treatments. The adventitious root sprouting in the seedlings was induced by injecting $\left(\mathrm{T}_{3}\right)$ the pathogen. The most suitable methods to inoculate $F$. solani $\mathrm{f}$. sp. passiflorae on passionfruit seedlings were the modified testtube screening methodology and the stem incision due to its homogeneity and replicability results. 
Key words: Nectria haematococca, colonization, disease incubation, pathogenicity. Thesaurus: aims.fao.org/es/agrovoc.

\section{INTRODUCIÓN}

El maracuyá (Passiflora edulis f. flavicarpa Degener) es una especie vegetal de gran importancia comercial, que pertenece a la familia Pasifloraceae. En Colombia, para el 2016, el área cultivada fue de 7.192 ha y la producción total superó las 119 mil toneladas, siendo los departamentos de Antioquia, Meta, Huila y Valle del Cauca los responsables del $74 \%$ de esta producción (Agronet, 2016). Esta planta es atacada por fitopatógenos, como bacterias, virus, nematodos y hongos patógenos, que afectan su fisiología y reducen el rendimiento (Castaño-Zapata, 2009; Fischer et al. 2010; Bueno et al. 2014). Entre las enfermedades más relevantes del maracuyá, se encuentra la secadera, cuyo agente causal es Nectria haematococca Berk. \& Broome [anamorfo: Fusarium solani f. sp. passiflorae sugerido por Bueno et al. (2014)] (Castaño-Zapata, 1994; Castaño-Zapata, 2009; Fischer et al. 2010; Silva et al. 2013; Preisigke et al. 2015).

Nectria haematococca (anamorfo: F. solani) es un hongo fitopatógeno, habitante natural del suelo, que puede causar pérdidas en el cultivo de maracuyá, entre 90 y 100\% (Torres et al. 2000); infecta las plantas, mediante la emisión de un tubo germinativo, que atraviesa los tejidos de las raíces y coloniza los vasos del xilema hasta obstruirlos e impide la translocación de agua y de nutrientes a otros órganos de la planta (Ortíz et al. 2014; Castaño-Zapata, 2015). Durante la transpiración, el hongo asciende fácilmente por los haces vasculares; en forma paulatina, la planta cierra los estomas, las hojas pierden turgencia, se marchitan, se desprenden y la planta, finalmente, muere, reduciendo el ciclo de vida del cultivo, en promedio a 15 meses, en Valle del Cauca (Ortíz \& Hoyos, 2012). Posteriormente, el hongo invade todos los tejidos de la planta muerta y empieza a esporular, reiniciando el ciclo de dispersión e infección (Castaño-Zapata, 2009). Una vez que inicia este proceso, el manejo del patógeno, mediante alternativas químicas o biológicas, se dificulta, debido a la formación de estructuras de supervivencia (clamidosporas), que pueden permanecer en el suelo, por largos periodos de tiempo y ser fácilmente diseminadas por la lluvia, el agua de riego y el viento (Nelson et al. 1994; Agrios, 2005; CastañoZapata, 2009; Silva et al. 2013).

El uso de cultivares resistentes es el método más apropiado para el manejo de enfermedades fungosas, como la secadera (Silva et al. 2013); sin embargo, para el proceso de evaluación y de selección de genotipos resistentes, es necesario inducir el desarrollo de los síntomas de la enfermedad, mediante un método de inoculación eficiente. Los métodos de inoculación artificial permiten observar variabilidad en los periodos de incubación y de latencia, el proceso de colonización, el mecanismo de patogénesis, edad óptima de susceptibilidad al agente causante de la enfermedad y optimización de tiempo y de recursos económicos (Castaño-Zapata, 1994; Ortíz \& Hoyos, 2016).

Para la selección de materiales resistentes de maracuyá y otros cultivos a Fusarium spp., diferentes métodos de inoculación han sido descritos en detalle (Lozovaya et al. 2004; Fischer et al. 2005; Narayanasamy, 2011; Ortíz \& Hoyos, 2016); no obstante, la comparación entre los métodos utilizados y su eficacia para la inoculación de $F$. solani f. sp. passiflorae aún está siendo estudiada, en las condiciones de Colombia. Por esta razón, la presente investigación tuvo como objetivo evaluar la eficiencia de cuatro métodos de inoculación para inducir los síntomas causados por Fusarium solani f. sp. passiflorae en plántulas de maracuyá, bajo condiciones controladas de luz y de temperatura.

\section{MATERIALES Y MÉTODOS}

Aislamiento y pruebas de patogenicidad del patógeno. El aislamiento monospórico de F. solani f. sp. passiflorae MViRi01, se obtuvo de un cultivo enfermo de maracuyá amarillo del predio productivo Dember, ubicado a $4^{\circ} 58^{\prime} 03,1$ " N y $75^{\circ} 53^{\prime} 54,8$ " W en el municipio de Santuario - Risaralda (Colombia), con altitud y temperatura promedio de $908 \mathrm{~m}$ s.n.m. y $27^{\circ} \mathrm{C}$, respectivamente. El aislamiento del patógeno, se realizó a partir de plantas enfermas de 12 meses de edad, en medio de cultivo Papa Dextrosa Agar (PDA), siguiendo las recomendaciones de Castaño-Zapata (1998); el cultivo monospórico, se obtuvo con el método de diluciones seriadas, en medio de cultivo Hojas de Clavel Agar (CLA), como lo describe Leslie \& Summerell (2006). La caracterización del hongo, se efectuó a través de microscopía óptica, complementada, con observación en microscopia electrónica de barrido ambienta $\left(\mathrm{ESEM}^{\mathrm{TM}}\right.$ ) (Robledo-Buriticá et al. 2017). Finalmente, se demostró la patogenicidad del hongo.

Material de propagación. A partir de frutos maduros de plantas sanas de maracuyá amarillo ( $P$. edulis f. flavicarpa Degenger), susceptibles a la secadera, procedentes del predio productivo Dember, con coordenadas $4^{\circ} 58^{\prime} 03,1^{\prime \prime}$ ' W y 7553'54.8' ' N, ubicado en el kilómetro 7 vía La Virginia - Apía, municipio de Santuario, Risaralda, se extrajo pulpa, que fue fermentada durante $72 \mathrm{~h}$ y después se retiró el mucilago. Las semillas fueron tratadas por el método de triple desinfestación, sumergiéndolas, de manera sucesiva, en abundante agua, alcohol al $70 \%$ y agua destilada estéril. Posteriormente, se realizó otra desinfestación con hipoclorito de sodio al $2 \%$, durante $2 \mathrm{~min}$, seguidas de un lavado con agua destilada estéril (French et al. 1980). Las semillas 
fueron sembradas en recipientes con suelo esterilizado y se incubaron bajo condiciones controladas, con temperatura promedio de $29^{\circ} \mathrm{C}$ y fotoperiodo de $12 \mathrm{~h}$.

\section{Métodos de inoculación.}

1. Incisión en el tallo $\left(\mathrm{T}_{1}\right)$ : Se utilizaron plántulas de P. edulis f. flavicarpa con un diámetro del cuello de la raíz superior a $6 \mathrm{~mm}$ y ocho hojas en promedio (7 a 8 semanas después de la siembra). La sección basal del tallo se desinfestó con etanol al $70 \%$. A $2 \mathrm{~cm}$, a partir del nivel del suelo, se realizó un corte en forma de bisel, con una cuchilla estéril, a una profundidad aproximada del $50 \%$ del diámetro del tallo. Sobre la herida, se colocó un segmento de $20 \mathrm{~mm}^{2}$ de PDA, con micelio de $F$. solani f. sp. passiflorae MViRi01. En las plántulas del control de solo, se colocó PDA en la incisión. La herida y el PDA fueron cubiertos con cinta Floraltex ${ }^{\circledR}$, adherida a presión. Finalmente, la plántula se sujetó a tres soportes plásticos perpendiculares al suelo, para evitar el volcamiento. Este método ha sido utilizado para la inoculación de Fusarium spp. en plántulas de maracuyá (Fischer et al. 2005; Ortíz \& Hoyos, 2012).

2. Inmersión de las raíces $\left(\mathrm{T}_{2}\right)$ : Se utilizaron plántulas de P. edulis f. flavicarpa con un número de ocho hojas en promedio (7 a 8 semanas después de la siembra). Las raíces de las plántulas se lavaron cuidadosamente, retirando todos los residuos de suelo visibles. Después, se realizó una poda cortando, aproximadamente, el $60 \%$ de la longitud de las raíces, utilizando tijeras desinfestadas con hipoclorito de sodio al $2 \%$, durante $3 \mathrm{~min}$. Luego, cada una de las plántulas fue sumergida hasta la base del tallo durante $24 \mathrm{~h}$, en una suspensión conidial de F. solani f. sp. passiflorae MViRi01, a una concentración de $1 \times 10^{6}$ conidios $/ \mathrm{mL}$, de agua destilada estéril. Las plántulas control, se podaron de la misma manera que las plántulas inoculadas y solo se sumergieron en agua destilada estéril por 24h. Finalmente, las plántulas fueron trasplantadas en vasos de aluminio de $500 \mathrm{~mL}$, que contenían suelo esterilizado en autoclave, a $121^{\circ} \mathrm{C}$ y $15 \mathrm{~atm}$, por $30 \mathrm{~min}$. Este método ha sido utilizado por Fischer et al. (2005).

3. Inyección en el tallo $\left(\mathrm{T}_{3}\right)$ : Se utilizaron plántulas de $P$. edulis f. flavicarpa con ocho hojas en promedio (7 a 8 semanas después de la siembra). La sección basal del tallo se desinfestó con etanol al $70 \%$. Con una jeringa de $1 \mathrm{~mL}$ y aguja de $26 \mathrm{~mm} \times 0,5 \mathrm{~mm}$, se inyectó a $2 \mathrm{~cm}$ desde el suelo, $0,1 \mathrm{~mL}$ de una suspensión conidial de $F$. solani f. sp. passiflorae MViRi01, a una concentración de $1 \times 10^{6}$ conidios $/ \mathrm{mL}$, de agua destilada estéril. Posteriormente, las plántulas se cubrieron con bolsas transparentes de polietileno. Las plántulas control fueron inyectadas con agua destilada estéril. Este método de inyección en el tallo ha sido empleado por Grausgruber et al. (1995), para inocular Fusarium spp., en plántulas de trigo.
4. Cribado en tubos de ensayo modificada $\left(T_{4}\right)$ : Se utilizaron plántulas de $P$. edulis f. flavicarpa con dos hojas verdaderas (3 semanas después de la siembra). En tubos de ensayo de boquilla lisa, se adicionaron $10 \mathrm{~mL}$ de agua, se recortó un círculo de papel filtro Whatman No. 2 y se introdujo en el tubo, formando una plataforma que se sumergió parcialmente en el agua. Luego, se sellaron los tubos con algodón y con papel aluminio y esterilizaron en autoclave, durante $15 \mathrm{~min}$, a $121^{\circ} \mathrm{C}$. Una vez fríos, en los tubos, se introdujeron las plántulas previamente desinfestadas en hipoclorito de sodio al $2 \%$, durante $2 \mathrm{~min}$, etanol al $70 \%$, por 50 s y lavado con agua destilada estéril. Finalmente, se colocó una sección del aislamiento en medio PDA, en contacto directo con el cuello de la raíz de la plántula y se selló el tubo con algodón y con papel aluminio. En el control, se utilizó PDA estéril sobre el cuello de la raíz. Este método fue sugerido, inicialmente, para realizar cribado en plántulas de trébol (Trifolium sp.), por Kelman et al. (1967).

Variables evaluadas. Se realizaron observaciones diarias durante 50 días, posteriores a inoculación; las variables evaluadas fueron incidencia de la enfermedad (número de plantas enfermas expresado en porcentaje) y el periodo de incubación del hongo (número de días transcurridos desde la inoculación hasta la manifestación de los síntomas, característicos de la enfermedad). Los síntomas fueron clasificados mediante la escala ordinal, sugerida por Ortíz \& Hoyos (2016), así: i) ausencia de síntomas, ii) marchitez moderada o clorosis, iii) marchitez severa, decoloración del tallo o defoliación y iv) muerte de la plántula.

Análisis de datos. Se utilizó un diseño experimental completamente al azar con tres repeticiones, la unidad experimental fue tres plántulas por repetición. Los datos, se sometieron a un análisis de varianza (ANAVA) y pruebas comparativas de promedio tipo Tukey al $5 \%$ de probabilidad, mediante el software estadístico R ( $\mathrm{R}$ development core team, 2014).

\section{RESULTADOS Y DISCUSIÓN}

Incidencia de la enfermedad. Los métodos de inoculación empleados reportaron diferencias estadísticas altamente significativas $(P<0,001)$, en la incidencia de la enfermedad acumulada a 50 días después de la inoculación (Tabla 1); sin embargo, los valores de esta variable no se acrecentaron en ningún método a partir del día 22 después de la inoculación (Figura 1A). El cribado en tubos de ensayo modificado $\left(T_{4}\right)$ presentó una tendencia de aumento lineal constante en la incidencia de la enfermedad hasta el cuarto día, con el $100 \%$ de plántulas enfermas (Figura 1A). La incisión en el tallo $\left(T_{1}\right)$ produjo un comportamiento similar a $T_{4}$, solo que la aparición de síntomas se presentó a partir del día 4 al 7 y alcanzó el $100 \%$ de incidencia a 21 días después de la inoculación (Figura 1A). Este método fue empleado por 
Fischer et al. (2005), quienes reportaron una incidencia del $60 \%$, al causar heridas para inocular $F$. solani, en plántulas de maracuyá, similar a lo obtenido por Forero et al. (2015), quienes registraron una incidencia de marchitez causada por $F$. oxysporum en plántulas de $P$. maliformis (2,5 meses de edad) del $40 \%$, mediante la técnica de inmersión de raíces. Con los tratamientos de inmersión de raíces $\left(T_{2}\right)$ e inyección en el tallo $\left(T_{3}\right)$, se obtuvieron valores máximos de incidencia, de 30 y $60 \%$, respectivamente (Tabla 1), en el día 19 y 10, después de la inoculación (Figura 1A). En T3, el desarrollo de la incidencia de la enfermedad, a partir del quinto día después de la inoculación, fue gradual y pausado (Figura 1A). En los tratamientos control de cada una de las metodologías evaluadas no se observaron síntomas de la enfermedad.

Tabla 1. Incidencia acumulada y desarrollo de síntomas de la enfermedad, en los cuatro métodos de inoculación.

\begin{tabular}{|l|c|c|c|c|}
\hline \multirow{2}{*}{\multicolumn{1}{|c|}{ Métodos de inoculación }} & \multirow{2}{*}{$\begin{array}{l}\text { Incidencia de la } \\
\text { enfermedad (\%) }\end{array}$} & \multicolumn{2}{|c|}{ Días después de la inoculación (ddi) } \\
\cline { 4 - 5 } & & Periodo de & $\begin{array}{c}\text { Síntomas } \\
\text { incubación }\end{array}$ & $\begin{array}{c}\text { Muerte de la } \\
\text { plántula }\end{array}$ \\
\hline$\left(\mathrm{T}_{2}\right)$ Inmersión de raíces & $30 \mathrm{~b}$ & $19 \mathrm{a}$ & $23,9 \mathrm{a}$ & $29,9 \mathrm{a}$ \\
\hline$\left(\mathrm{T}_{1}\right)$ Incisión en el tallo & $100 \mathrm{a}$ & $7,2 \mathrm{~b}$ & $9,9 \mathrm{~b}$ & $12,3 \mathrm{~b}$ \\
\hline$\left(\mathrm{T}_{3}\right)$ Inyección en el tallo & $60 \mathrm{ab}$ & $6,16 \mathrm{~b}$ & $7,2 \mathrm{bc}$ & $12,2 \mathrm{~b}$ \\
\hline$\left(\mathrm{T}_{4}\right)$ Cribado en tubos de ensayo & $100 \mathrm{a}$ & $2,4 \mathrm{c}$ & $5,0 \mathrm{c}$ & $6,2 \mathrm{c}$ \\
\hline Nivel de significancia $(\mathrm{P})$ & $<0,001$ & $<0,001$ & $<0,001$ & $<0,001$ \\
\hline
\end{tabular}

*Valores con la misma letra no difieren estadísticamente, según la prueba comparativa tipo Tukey al 5\%.

\section{A}
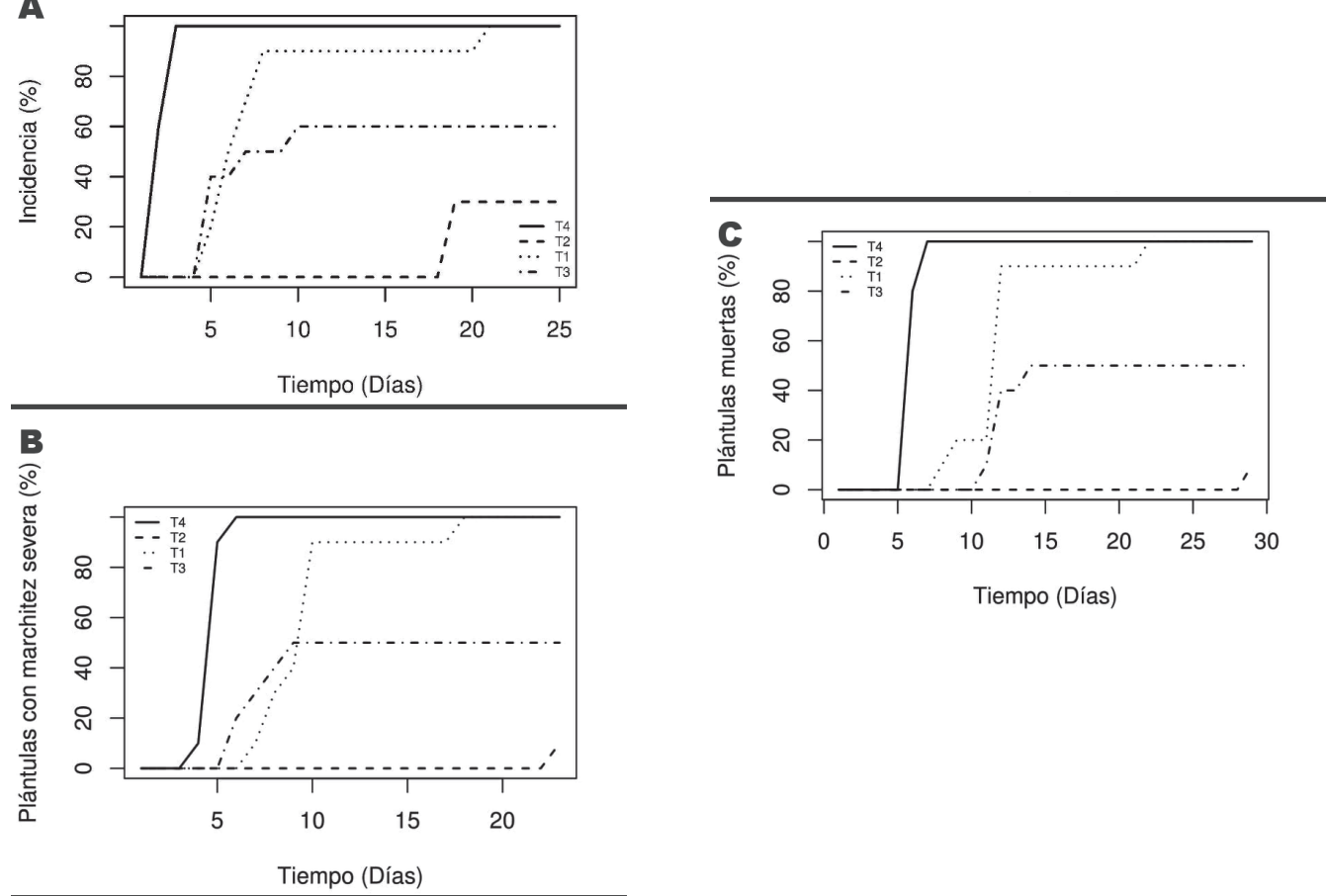

Figura 1. A. Incidencia de la secadera causada por Fusarium solani f. sp. passiflorae, en plántulas de maracuyá (P. edulis var. flavicarpa), a través del tiempo; B. Porcentaje de plántulas de maracuyá (P. edulis f. flavicarpa) con síntomas severos de la secadera, causada por $F$. solani f. sp. passiflorae y C. Plántulas de maracuyá (P. edulis var. flavicarpa) muertas por infección de Fusarium solani. $\mathbf{T}_{1}$. Incisión en el tallo, $\mathbf{T}_{2}$. Inmersión de raíces, $\mathbf{T}_{3}$. Inyección en el tallo, $\mathbf{T}_{4}$. Cribado en tubos de ensayo modificado. 
Periodo de incubación. El periodo de incubación de F. solani f. sp. passiflorae en plántulas de maracuyá mostró diferencias estadísticas altamente significativas $(P<0,001)$, entre los tratamientos. A medida que crecen las plantas aumenta el contenido de suberina y de cutina, dos compuestos metabólicos que ayudan a bloquear la entrada de hongos patógenos y de bacterias (Podila et al. 1988; Castaño-Zapata, 1994; Taiz \& Zeiger, 2010); sin embargo, al causar heridas en la corteza y especialmente en raíces, se facilita la infección de F. solani (Fischer et al. 2005).

La aparición de síntomas tardó menos tiempo en plántulas, cuyo punto de inoculación fue la base del tallo; sin embargo, todos los tratamientos inoculados con el hongo mostraron síntomas iniciales de deshidratación leve, clorosis en las hojas bajeras y coloración parda en la base del tallo (Figuras 2, 3, 4 y 5); en los tratamientos de control de cada una las metodologías evaluadas estos síntomas no se presentaron. En plántulas inoculadas en tubos de ensayo ( $\left.\mathrm{T}_{4}\right)$, el tejido adyacente al punto de infección mostró hipertrofia y desarrollo superficial de micelio (Figura 4); con este método, el hongo presentó un periodo de incubación de 2,4 días (Tabla 1). El mayor tiempo fue registrado en el método de inmersión de raíces (Figura 3), cuyo periodo de incubación del hongo fue de 19 días (Tabla 1).
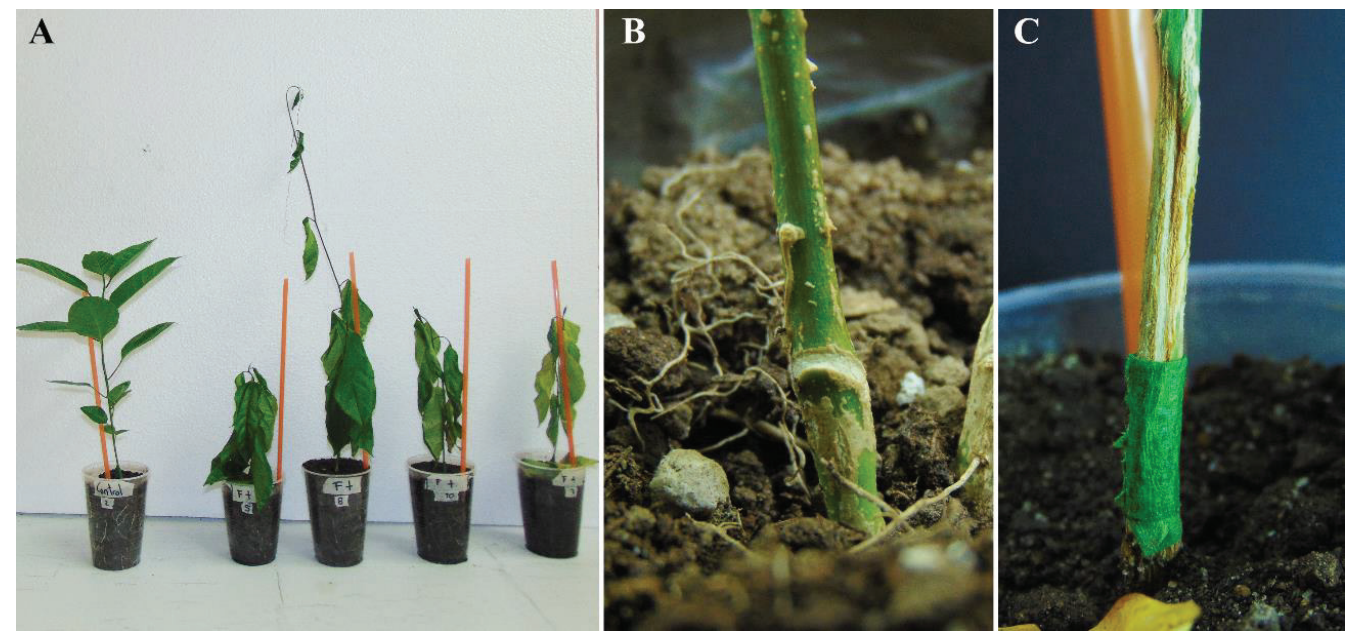

Figura 2. Inoculación de Fusarium solani f. sp. passiflorae en plántulas de maracuyá (Passiflora edulis f. flavicarpa), por el método de incisión en el tallo y deposición de PDA con el patógeno ( $\left.\mathrm{T}_{1}\right)$. A. Plántula sana o control (izquierda) y plántulas con síntomas de la secadera causada por F. solani f. sp. Passiflorae; B. Cicatrización de la incisión del tallo en una plántula de control y C. Estrangulamiento y decoloración del tallo en una plántula inoculada.
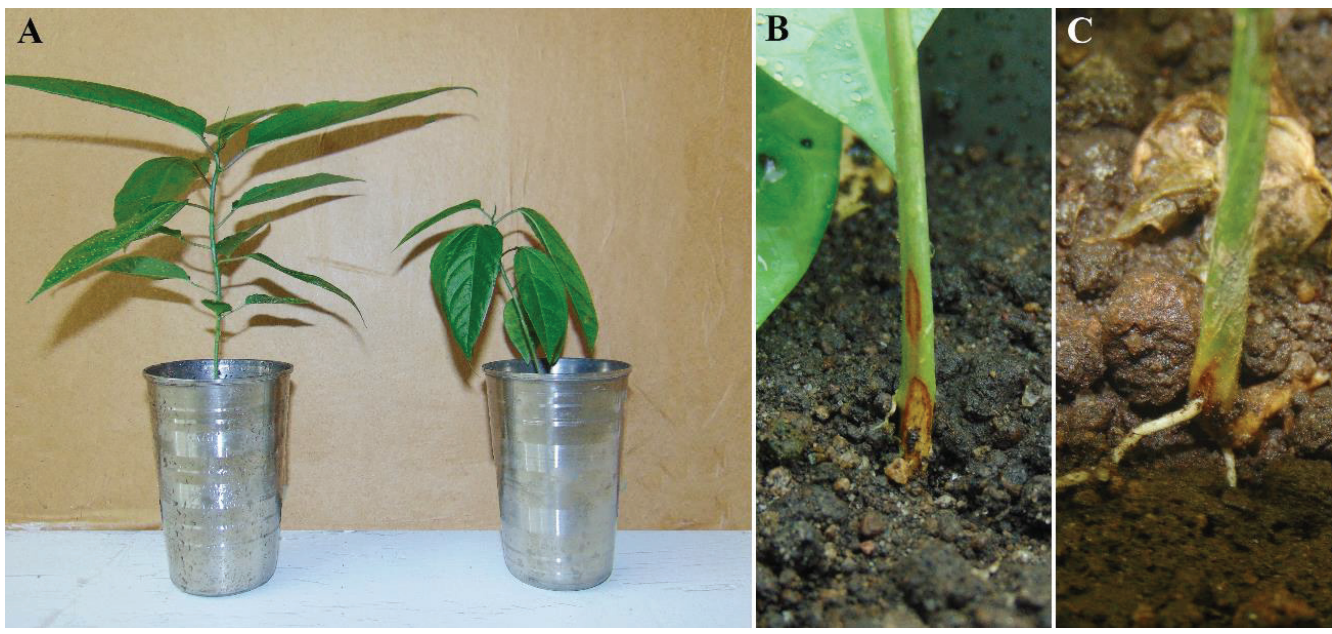

Figura 3. Inoculación de Fusarium solani f. sp. passiflorae en plántulas de maracuyá (Passiflora edulis f. flavicarpa), por el método inmersión de raíces, en una suspensión conidial de $1 \times 10^{6}$ conidios $/ \mathrm{mL}$, de agua destilada esteril (T2). A. Plántula sana o control (izquierda) y plántula con síntomas de la secadera; B-C. Inicio del estrangulamiento y decoloración del tallo de una plántula inoculada. 


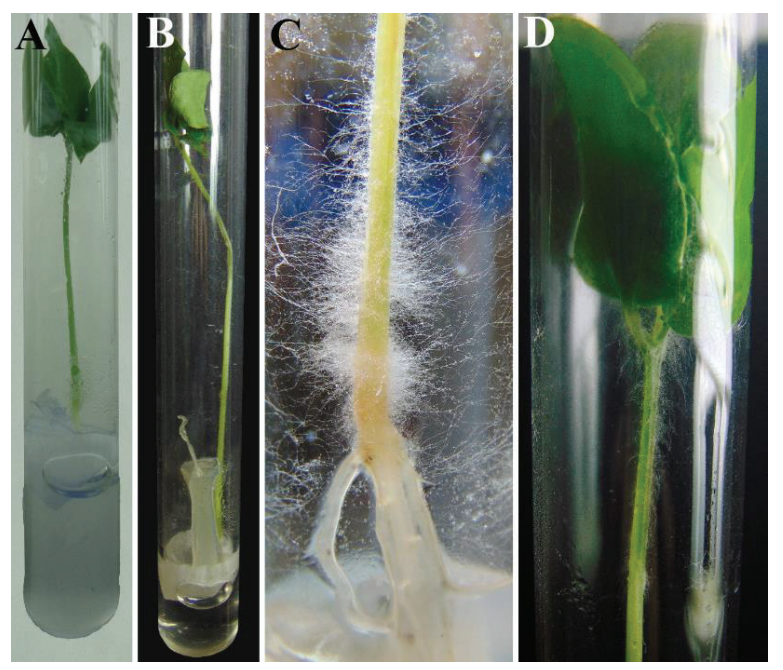

Figura 4. Inoculación de Fusarium solani f. sp. passiflorae en plántulas de maracuyá (Passiflora edulis f. flavicarpa), por el método de cribado en tubos de ensayo modificado $\left(\mathrm{T}_{4}\right)$. A. Plántula sana o control; B. plántula con síntomas de la secadera; C. Crecimiento del micelio sobre el cuello de la raíz Y D. Crecimiento del micelio sobre el tallo y peciolos.

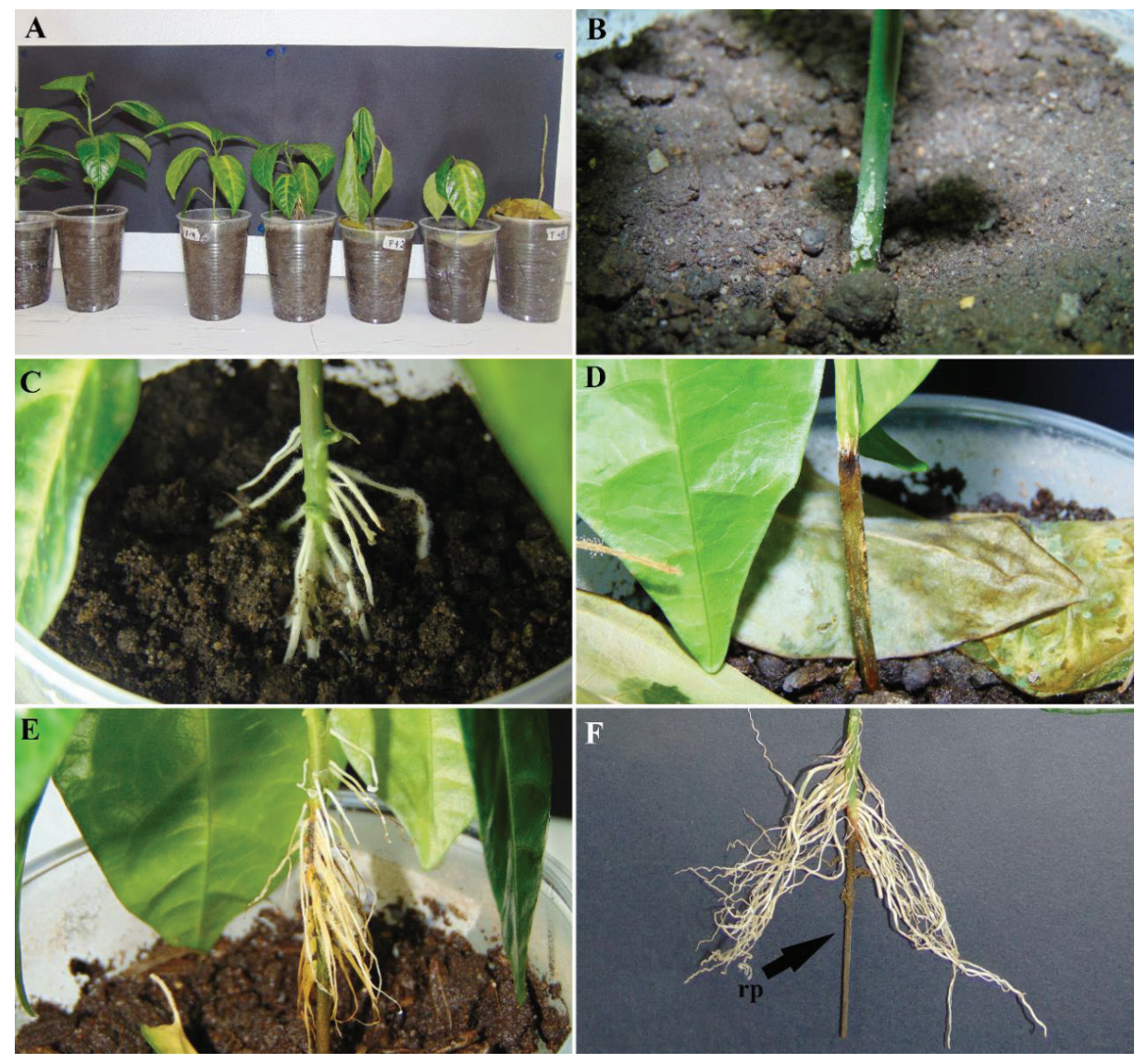

Figura 5. Inoculación de Fusarium solani f. sp. passiflorae en plántulas de maracuyá (Passiflora edulis f. flavicarpa), por el método de inyección en el tallo, de una suspensión conidial a $1 \times 10^{6}$ conidios $/ \mathrm{mL}$, de agua destilada estéril ( $\left.T_{3}\right)$. A. Plántula sana o control (izquierda) y plántulas con síntomas de la secadera; B. Cicatrización de inyección en el tallo en una plántula control; C y E. Raíces adventicias de plántulas inoculadas; D. Estrangulamiento y decoloración del tallo de una plántula inoculada y F. Pudrición de la raíz pivotante $(r p)$ de una plántula con desarrollo de raíces adventicias. 
El periodo de incubación de $F$. solani f. sp. passiflorae inoculado mediante inyección en el tallo $\left(\mathrm{T}_{3}\right)$ fue de 6,16 días (Tabla 1), valor cercano al registrado en el método de la incisión en el tallo $\left(\mathrm{T}_{1}\right)$, el cual, presentó un valor de 7,2 días (Tabla 1). Este comportamiento es similar al reportado por Fischer et al. (2005), quienes inocularon $F$. solani, mediante incisión en el tallo en plántulas de maracuyá, registrando un periodo de incubación de 7 días.

Síntomas severos. El número de días promedio desde la inoculación hasta la presencia de los síntomas de marchitez severa presentó diferencias estadísticas altamente significativas $(P<0,001)$, entre los métodos de inoculación evaluados (Tabla 1). El desarrollo de síntomas foliares solo se presentan cuando el patógeno ha invadido los haces vasculares de peciolos y de hojas, ya que son determinados por la extensión de la colonización fúngica (Rodríguez- Molina et al. 2003).

El tiempo para la expresión de síntomas severos fue menor en plántulas, cuyo punto de infección fue la base del tallo. La inoculación, mediante el cribado en tubos de ensayo modificado $\left(\mathrm{T}_{4}\right)$, aceleró el marchitamiento, entre 4 y 6 días (Figura 1B). En este método, al igual que en la incisión del tallo, todas las plántulas inoculadas mostraron síntomas de marchitez severa (Figuras 2 y 4). En los métodos inmersión de raíces $\left(T_{2}\right)$ e inyección en el tallo $\left(T_{3}\right)$, el porcentaje de plántulas con marchitez severa fue respectivamente de 10 y $50 \%$, a los 23 y 9 días después de inoculación (Figura 1B). En los tratamientos control de las metodologías de incisión e inyección en la base del tallo, se pudo apreciar la cicatrización de las heridas, provocadas por la metodología; sin embargo, los síntomas de la enfermedad no se presentaron.

Muerte de las plántulas. El número de días promedio desde la inoculación hasta la muerte de la plántula presentó diferencias estadísticas altamente significativas $(P<0,001)$, en los métodos de inoculación evaluados (Tabla 1). Las plántulas muertas mostraron estrangulamiento, defoliación, pudrición seca y colonización del hongo en diversos tejidos (Figura 2, 3, 4 y 5).

El cribado en tubos de ensayo modificado $\left(\mathrm{T}_{4}\right)$ y la incisión en el tallo $\left(T_{1}\right)$ mostraron resultados con baja desviación estándar y fácilmente replicables. Todas las plántulas inoculadas en tubos de ensayo murieron entre 6 y 7 días después de la inoculación (Figura 1C), con micelio del hongo en todos los tejidos de la plántula (Figura 4). La misma mortandad ocurrió con el método de incisión en el tallo a los 23 días después de la inoculación; sin embargo, el 90\% de las plántulas murió 12 días después de la inoculación, sin presencia visible de micelio del hongo, sobre la superficie de tejidos (Figura 1 y 2). Los tratamientos de control de cada una las metodologías evaluadas no presentaron muerte de las plántulas.
La muerte del $50 \%$ de la población inoculada, mediante inyección en el tallo $\left(\mathrm{T}_{3}\right)$, ocurrió entre los 12 y 13 días después de la inoculación, con micelio visible en la superficie del tallo (Figura 1 y 5). La muerte del $10 \%$ de las plántulas inoculadas, mediante inmersión de raíces $\left(T_{2}\right)$, ocurrió 29 días después de la inoculación, sin presencia de micelio del hongo en la superficie de los tejidos (Figura 1 y 3 ).

Estrangulamiento del tallo. Otros estudios reportan el estrangulamiento ascendente y descendente desde la corona de la raíz de las plántulas de maracuyá, inoculadas con $F$. solani (Rodríguez- Molina et al. 2003; Fischer et al. 2005; Ortíz y Hoyos, 2016); sin embargo, el método de cribado en tubos de ensayo modificado $\left(\mathrm{T}_{4}\right)$ demostró la capacidad de $F$. solani f. sp. passiflorae para colonizar diversos tejidos de la planta y causar estrangulamiento ascendente, desde la base del tallo, cubriendo el $50 \%$ de su longitud o descendente, desde el meristemo apical, cubriendo el 25\% del tallo (Figura 4). Los demás tratamientos mostraron estrangulamiento ascendente, hasta el primer tercio del tallo (Figura 2, 3 y 5). Este mecanismo es característico de los hongos causantes de marchitez vascular, ya que la carga electrostática del hongo es comúnmente negativa al igual que las paredes celulares de las plantas, por lo que su desplazamiento interno se facilita a favor de la corriente de transpiración (CastañoZapata, 1994). En los tratamientos de control de cada una las metodologías evaluadas no se presentaron síntomas de estrangulamiento.

Emisión de raíces adventicias. La emisión de raíces adventicias, se evidenció en el $30 \%$ de las plántulas inoculadas, mediante la inyección en el tallo ( $\left.T_{3}\right)$, cultivadas con temperatura promedio de $29^{\circ} \mathrm{C}$, humedad ambiental de $100 \%$ y fotoperiodo de 12h (Figura 5 C, D, E y F); la infección progresó descendentemente, causando pudrición seca en la raíz principal, pero las plántulas no murieron durante los 50 días de evaluación (Figura 5F). En el tratamiento de control, de la metodología de inyección en el tallo, no se observó la formación de raíces adventicias. Grausgruber et al. (1995) evaluaron el método de inyección, inoculando a Fusarium graminearum en plantas de trigo y concluyeron que este método no es efectivo, por tener complicaciones cuando se pretende realizar la inoculación con una suspensión de micelio y de esporas del hongo.

La emisión de raíces adventicias en tallos ha sido referida como una causa del aumento de la concentración de etileno en la planta; en casos favorables, no se desarrollan los síntomas de la enfermedad o son reducidos (Castaño-Zapata, 1994; Taiz \& Zeiger, 2010). La producción de etileno está generalmente asociado a la abscisión, la senescencia y la maduración de los frutos; sin embargo, otras causas, como las heridas, las enfermedades, el estrés por alta humedad, la sequía y el estrés por altas temperaturas pueden aumentar, 
considerablemente, su producción (Taiz \& Zeiger, 2010). El etileno puede regular la expresión de varios genes específicos con respuesta a patógenos, incluyendo los que codifican la celulosa. Además, la combinación de etileno con la hormona denominada ácido jasmónico permiten la activación de varios genes de defensa de la planta, especialmente, para la protección contra patógenos necrotróficos, que habitan el suelo (Taiz \& Zeiger, 2010).

En conclusión, aunque los métodos de inoculación empleados en este estudio indujeron los síntomas de la enfermedad, los de cribado e incisión en el tallo fueron los más eficientes, debido a la homogeneidad en los resultados obtenidos, incidencia de la enfermedad y el periodo de incubación en condiciones de laboratorio. Los autores recomiendan replicar este estudio bajo condiciones in situ, para simular las condiciones de campo.

Conflictos de intereses: El manuscrito fue preparado y revisado con la participación de todos los autores, quienes declaramos que no existe conflicto de intereses, que ponga en riesgo la validez de los resultados presentados. Financiación: Esta investigación fue financiada por la Universidad de Caldas y realizada dentro de sus instalaciones.

\section{BIBLIOGRAFÍA}

1. AGRIOS, G.N. 2005. Plant pathology. 5 ed. Burlington: Elsevier Academic Press (Estados Unidos). 952p.

2. AGRONET. 2016. Red de información y comunicación del sector agropecuario. Disponible desde Internet en: http://www.agronet.gov.co/estadistica/Paginas/ default.aspx (con acceso 07/01/2017).

3. BUENO, C.J.; FISCHER, I.H.; ROSA, D.D.; FIRMINO, A.C.; HARAKAVA, R.; OLIVEIRA, C.M.G.; FURTADO, E.L. 2014. Fusarium solani f. sp. passiflorae: a new forma specialis causing collar rot in yellow passion fruit. Plant Pathology (Reino Unido). 63(2):382-389.

4. CASTAÑO-ZAPATA, J. 1994. Principios básicos de fitopatología. 2 ed. Zamorano Academic Press, Honduras. 538p.

5. CASTAÑO-ZAPATA, J. 1998. Prácticas de laboratorio de fitopatología. Centro Editorial Universidad de Caldas. Manizales- Colombia. 103p.

6. CASTAÑO-ZAPATA, J. 2009. Enfermedades importantes de las pasifloráceas en Colombia. En: Miranda, D.; Fischer, G.; Carranza, C.; Magnitskiy, S.; Casierra, F.; Piedrahíta, W.; Flórez, L (eds.). Cultivo, Poscosecha y Comercialización de las Pasifloráceas en Colombia:
Maracuyá, Granadilla, Gulupa y Curuba. Soc. Col. Ciencias Hort. p.223-245.

7. CASTAÑO-ZAPATA, J. 2015. Principios básicos de hongos fitopatógenos. Centro Editorial Universidad de Caldas (Colombia). 362p.

8. FISCHER, I.; LOURENCO, S.; MARTINS, M.; KIMATI, H.; AMORIN, L. 2005. Seleção de plantas resistentes e de fungicidas para o controle da podridão do colo do maracujazeiro causada por Nectria haematococca. Fitopatología Brasileira. 30:250-258.

9. FISCHER, I.H.; ALMEIDA, A.M.; FILETI, M.; BERTANI, R.M.; ARRUDA, M.C.; BUENO, C.J. 2010. Evaluation of passifloraceas, fungicides and Trichoderma for passionfruit collar rot handling, caused by $\mathrm{Nec}$ tria haematococca. Rev. Brasileira de Fruticultura. 32(3):709-717.

10. FORERO, R.; ORTÍZ, E.; LEÓN, E.; GÓMEZ, J.C.; CARVAJAL-HOYOS, L. 2015. Análisis de la resistencia a Fusarium oxysporum en plantas de Passiflora maliformis L. Rev. Col. Ciencias Hortícolas. 9(2):197208.

11. FRENCH, E.; TEDDY, R.; HERBERT, T. 1980. Métodos de investigación fitopatológica y aislamiento de fitopatógenos. Instituto Interamericano de Ciencias Agrícolas (Costa Rica). p.142-186.

12. GRAUSGRUBER, H.; LEMMENS, M.; BURSTMAYR, H.; RUCKENBAUER, P. 1995. Evaluation of inoculation methods for testing Fusarium head blight resistance of winter wheat on single plant basis. Bondenkultur (Austria). 46:39-49.

13. KELMAN, A. 1967. Source book of laboratory exercises in plant pathology. APS. W. Freeman \& Company (Estados Unidos). 387p.

14. LESLIE, J.F.; SUMMERELL, B.A. 2006. The Fusarium laboratory manual. Blackwell Publishing, lowa, USA. 388p.

15. LOZOVAYA, V.v.; LYGIN, A.V; HARTMAN, G.L.; WIDHOLM, J.M. 2004. Biochemical response of soybean roots to Fusarium solani f.sp. glycines infection. Crop Science (Estados Unidos). 44(3):819-826.

16. NARAYANASAMY, P. 2011. Detection of fungal pathogens in plants. In: Fungal Pathogens. Springer \& Dordrecht (India). 200p. 
17. NELSON, P.E.; DIGNANI, M.C.; ANAISSIE, E.J. 1994. Taxonomy, biology, and clinical aspects of Fusarium species. Clinical Microbiology Reviews (Estados Unidos). 7(4):479-504.

18. ORTíZ, E.; CRUZ, M.; MELGAREJO, L.M.; MARQUÍNEZ, X.; HOYOS-CARVAJAL, L. 2014. Histopathological features of infections caused by Fusarium oxysporum and F. solani in purple passionfruit plants (Passiflora edulis Sims). Summa Phytopathol. (Brasil). 40(2):134-140.

19. ORTíZ, E.; HOYOS, L. 2012. Description of the symptomatology associated with fusariosis and its comparison with other diseases for the purple passion fruit (Passiflora edulis Sims.) in the Sumapaz region (Colombia). Rev. Col. Ciencias Hort. 6(1):110-116.

20. ORTíZ, E.; HOYOS, L. 2016. Standart methods for inoculations of F. oxysporum and F. solani in Passiflora. African J. Agricultural Res. (Nigeria). 11(17):15691575.

21. PODILA, G.K.; DICKMAN, M.B; KOLATTUKUDY, P.E. 1988. Transcriptional activation of a cutinase gene in isolated fungal nuclei by plant cutin monomers. Science (Estados Unidos). 242(4880):922-925.

22. PREISIGKE, S. DA C.; MARTINI, F.V.; ROSSI, A.A.B.; SERAFIM, M.E.; BARELLI, M.A.A.; DA LUZ, P.B.; ARAUJO, K.L.; NEVES, L.G. 2015. Genetic variability of Passiflora spp. against collar rot disease. Australian J. Crop Science. 9(1):69-74.

23. $\mathrm{R}$ development Core team. 2014. A language and environment for statistical computing. Vienna: R Foun- dation for Statistical Computing. Disponible desde Internet en: http://www.R-project.org/.

24. ROBLEDO-BURITICÁ, J.; ÁNGEL-GARCÍA, C.; CASTAÑO-ZAPATA, J. 2017. Environmental scanning electron microscopy of the infection process of Fusarium solani f. sp. passiflorae in seedlings of passionfruit (Passiflora edulis f. flavicarpa). Rev. Acad. Colomb. Cienc. Ex. Fis. Nat. (Colombia). 41(159):213-220.

25. RODRÍGUEZ-MOLINA, M.; MEDINA, I.; TORRES-VILLA, L.; CUARTERO, J. 2003. Vascular colonization patterns in susceptible and resistant tomato cultivars inoculated with Fusarium oxysporum f.sp. lycopersici races 0 and 1. Plant Pathology (Reino Unido). 52:199-203.

26. SILVA, A.; OLIVEIRA, J.; HADDAD, F.; FERRAZ, F.; NUNNES, O.; SANTOS, S.; PEREIRA, M.; FREITAS, P. 2013. Identification of passion fruit genotypes resistant to Fusarium oxysporum f. sp. passiflorae. Tropical Plant Pathology (Brasil). 38(3):236-242.

27. TAIZ, L.; ZEIGER, E. 2010. Plant physiology. 5th. Edition. Sinauer Associates (Estados Unidos). 778p.

28. TORRES, C.M.; SÁNCHEZ, M.; BRAVO, N.; MARMOLEJO, F.; GÓMEZ, E.D. 2000. Enfermedades fungosas y bacterianas en el cultivo de maracuyá Passflora edulis var. flavicarpa Degener en dos agroecosistemas. Fitopatología Colombiana. 26(2):47-54.

Recibido: Noviembre 15 de 2017

Aceptado: Marzo 27 de 2018

Cómo citar:

Ángel-García, C.; Robledo-Buriticá, J.; Castaño-Zapata, J. 2018. Comparación de métodos de inoculación de Fusarium solani f. sp. passiflorae en plántulas de maracuyá (Passiflora edulis f. flavicarpa). Rev. U.D.C.A. Act. \& Div. Cient. 21(1): 23-31. 